\title{
Pulmonary atresia with ventricular septal defect and major aortopulmonary collateral arteries Effect of systemic pulmonary anastomosis
}

\author{
SHEILA G HAWORTH, * PHILIP G REES, JAMES F N TAYLOR, \\ FERGUS J MACARTNEY, MARC DE LEVAL, JAROSLAV STARK
}

From the Thoracic Unit, The Hospital for Sick Children, Great Ormond Street, London

SUMMARY In nine patients with pulmonary atresia, ventricular septal defect, and major aortopulmonary collateral arteries, the effect of a systemic-pulmonary anastomosis on the lung was studied by comparison of pre- and postoperative cine angiograms. Selective injections into the collateral arteries were performed in all patients and the source of blood supply to each bronchopulmonary segment was sought. Central pulmonary arteries were present in six children and absent in three, as confirmed at thoracotomy. After insertion of a shunt, central pulmonary arteries increased in size, but the intrapulmonary vessels with which they connected remained abnormally small and were frequently stenosed. In addition, in each case the central pulmonary arteries increased flow to only five to 11 segments of lung. In the absence of central pulmonary arteries, shunting to a hilar or a lobar pulmonary artery increased perfusion to five to nine segments of lung per case. In all these three cases the pulmonary arteries at lobar level showed aneurysmal dilatation proximal to a severe stenosis. Sixty-eight per cent of collateral arteries were stenosed. The findings suggest that in this anomaly, when the central pulmonary arteries are hypoplastic, the intrapulmonary branches are also hypoplastic, emphasising the need for early surgical intervention to increase blood flow while the lung still has growth potential. Further, one collateral artery may connect with at least as many bronchopulmonary segments as does a central pulmonary artery, and the peripheral intrapulmonary arteries with which it connects may appear at least as normal angiographically as do vessels connected to central pulmonary arteries. These observations suggest that segments of lung connected to collaterals alone should, and sometimes can, be connected to central pulmonary arteries, the aim being to produce a unifocal blood supply as a prelude to total correction.

In pulmonary atresia with ventricular septal defect and major aortopulmonary collateral arteries, recent anatomical studies have shown that the proportion of bronchopulmonary segments connected to central pulmonary arteries is variable and can be a minority of segments. ${ }^{1}$ Nevertheless, a systemic-pulmonary anastomosis is generally performed in the hope that an increase in pulmonary blood flow will promote arterial growth and improve the patient's clinical condition. Even if no central pulmonary artery is present, an anastomosis may be made to an intrapulmonary vessel.

The pre- and postoperative cine angiograms of nine patients with successful systemic-pulmonary anastomoses were reviewed in order to assess the $\star$ Partly supported by the British Heart Foundation. Received for publication 16 July 1980 proportion of lung which had received an increase in blood flow, the appearance of the intrapulmonary vessels, and their capacity for growth, in relation to the clinical response.

\section{Clinical features}

The nine patients described had a modified BlalockTaussig shunt performed using polytetrafluoroethylene (Gore-Tex), rather than a Blalock-Taussig shunt using a subclavian artery, as is our usual practice. To assess the results achieved with a Gore-Tex shunt, pre- and postoperative cine angiocardiograms were performed. These angiocardiograms were used in the present study.

Nine patients with pulmonary atresia, ventricular septal defect, and major aortopulmonary collateral 
arteries had a total of 13 shunts (Table). Four patients had a second shunt to the contralateral lung, the indication being shunt occlusion in one case (case 1) and progressive cyanosis despite a functioning shunt in the other three. A modified Blalock-

\section{Table Clinical data}

\begin{tabular}{|c|c|c|c|c|}
\hline $\begin{array}{l}\text { Case } \\
\text { no. }\end{array}$ & Age at operation & $\begin{array}{l}\text { No. collater } \\
\text { preoperative } \\
\text { Right lung }\end{array}$ & $\begin{array}{l}\text { als seen } \\
\text { ly } \\
\text { Left lung }\end{array}$ & $\begin{array}{l}\text { Central } \\
\text { pulmonary } \\
\text { arteries }\end{array}$ \\
\hline 1 & $\begin{array}{l}1 \mathrm{mth} \\
1 \mathrm{y} 8 \mathrm{mth}\end{array}$ & 3 & 2 & + \\
\hline 2 & $8 \mathrm{mth}$ & 2 & 1 & 一 \\
\hline 3 & 1 y $4 \mathrm{mth}$ & 2 & 1 & + \\
\hline 4 & $\begin{array}{l}1 \text { y } 10 \mathrm{mth} \\
2 \text { y } 10 \mathrm{mth}\end{array}$ & 3 & 1 & - \\
\hline 5 & $\begin{array}{l}2 \mathrm{y} \\
7 \mathrm{y}\end{array}$ & 3 & 1 & - \\
\hline 6 & $\begin{array}{l}4 y \\
9 y\end{array}$ & 4 & 1 & Missed \\
\hline 7 & $5 y$ & 3 & 1 & + \\
\hline 8 & $6 y$ & 1 & 1 & + \\
\hline 9 & $15 \mathrm{y}$ & 3 & 1 & + \\
\hline
\end{tabular}

Abbreviations: + , demonstrated by angiography; - , not present at thoracotomy.

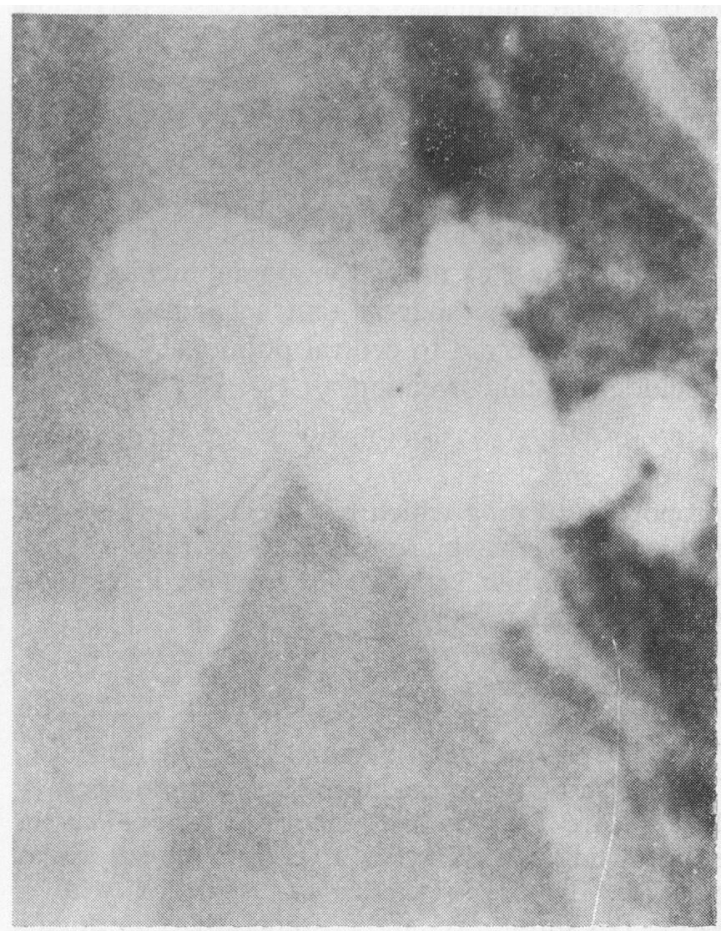

Fig. 1 Case 2. Selective injection into a collateral artery perfusing the lingula and three segments of the left lower lobe shows dilated and tortuous intrapulmonary vessels in which the pressure was equal to the systemic arterial pressure.

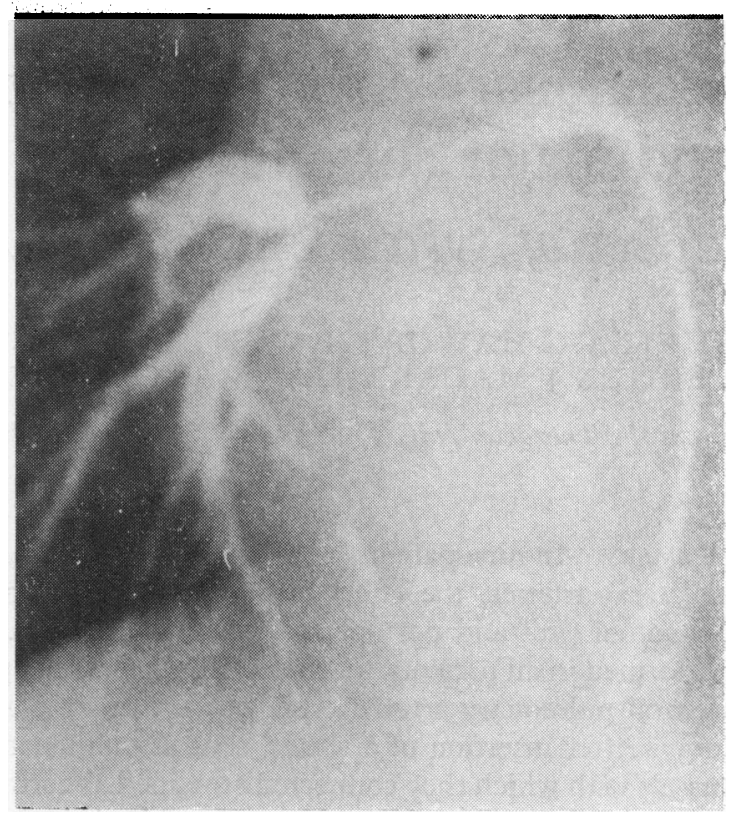

Fig. 2 Case 8. Selective injection into a collateral artery with a long stenosed segment.

Taussig shunt between a subclavian and pulmonary artery was performed in 10 instances. $^{23} \mathrm{~A}$ central shunt from ascending aorta to the main pulmonary artery was performed on three occasions. Gore-Tex was used for 11 shunts and woven Dacron for two.

The aim of surgery was to promote pulmonary arterial growth and development, rather than to improve arterial oxygen saturation. After operation there was a distinct improvement in exercise tolerance and well-being. There was, however, no significant change in either haemoglobin concentration or systemic arterial oxygen tension in the group.

\section{Investigations}

All patients had at least one cardiac catheterisation performed before and after the only, or first, shunt procedure (Table). The time interval between surgery and investigation varied between seven months and two years (mean $=14.7$ months). Biplane cine angiography was performed in all patients, save one in whom biplane Elema roll films were used at the preoperative study. At the preoperative study, collateral arteries were injected selectively in all save two patients. A total of 18 vessels was injected and the pressure in the collateral artery was measured in 11. Postoperatively, the shunt was injected in all studies except one. 
On reviewing the cine angiograms of each case before and after operation, the origin, course, and branches of the central pulmonary arteries and the collateral arteries were mapped on a diagram of the bronchial branching pattern. ${ }^{4}$ The size and shape of each vessel was noted, particular attention being given to the presence of stenoses.

An attempt was made to measure, before and after operation, the size of the same vessel in all cases, that vessel being either an extrapulmonary, lobar, or segmental pulmonary artery. This was abandoned because of the considerable variation in arterial anatomy caused by the presence of stenoses and localised arterial dilatations. Such abnormalities were generally unrelated to the site of the aortopulmonary anastomosis.

\section{Results}

\section{HAEMODYNAMIC FINDINGS}

Fourteen collateral arteries were catheterised at the pre- and postoperative cardiac catheterisation studies. The pressure within the collateral artery exceeded $45 / 30 \mathrm{mmHg}$ in all, and was equal to the systemic arterial pressure in six. Angiocardiography, however, showed that the pressure had been measured proximal to a stenosis in all save three instances. The exceptions included two colateral arteries in case 2 , where a high collateral arterial pressure was associated with angiographic features consistent with a diagnosis of pulmonary vascular obstructive disease (Fig. 1). Central pulmonary arterial pressure was measured postoperatively in only two cases. It was equal to the systemic arterial pressure in case 1, proximal to a severe stenosis, and measured $50 / 30 \mathrm{mmHg}$ in case 9 without a distal stenosis.

\section{ANGIOCARDIOGRAPHY}

(1) Collateral arteries

In all nine cases a total of 36 collateral arteries entered the lung, 34 being shown preoperatively

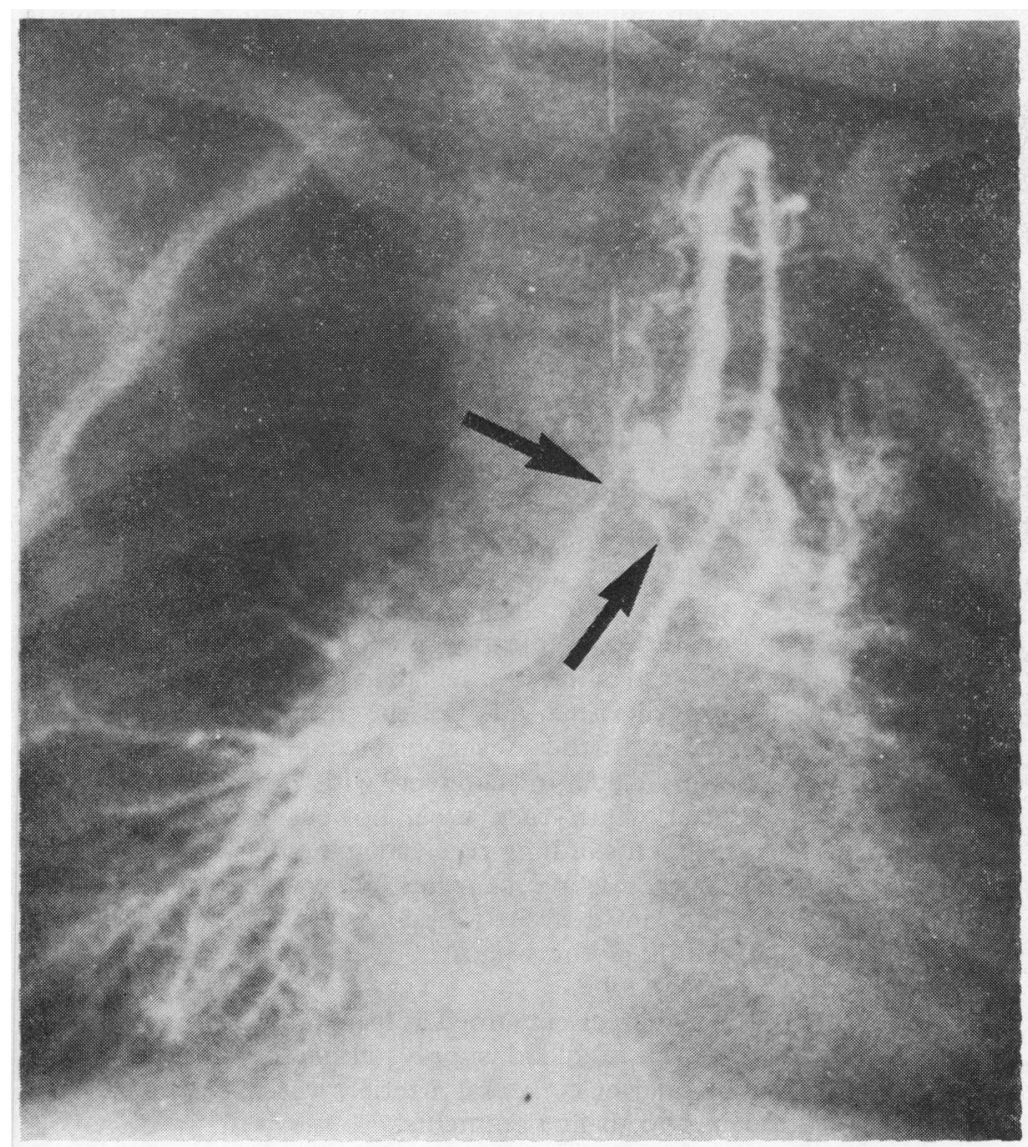

Fig. 3 Case 5. Selective injection into a collateral artery which divides to connect with four segmental arteries of the right lung and supplies at least six segmental arteries of the left lung. The segmental arteries appear abnormally small. Stenoses $(\rightarrow)$. 
(Table). Some collaterals branched near their origin from the aorta.

Stenoses: these were common. Thirteen collaterals had a narrowed segment between the aorta and lung (Fig. 2 and 3). A further eight collaterals had a more localised constriction where the collateral anastomosed with an intrapulmonary artery (Fig. 4). Three collaterals had a narrow origin from the aorta. 'Connections: preoperatively, collateral arterial injections showed central pulmonary arteries in five patients. A collateral anastomosed with the left pulmonary artery in three cases, and the right pulmonary artery in one. The source of supply

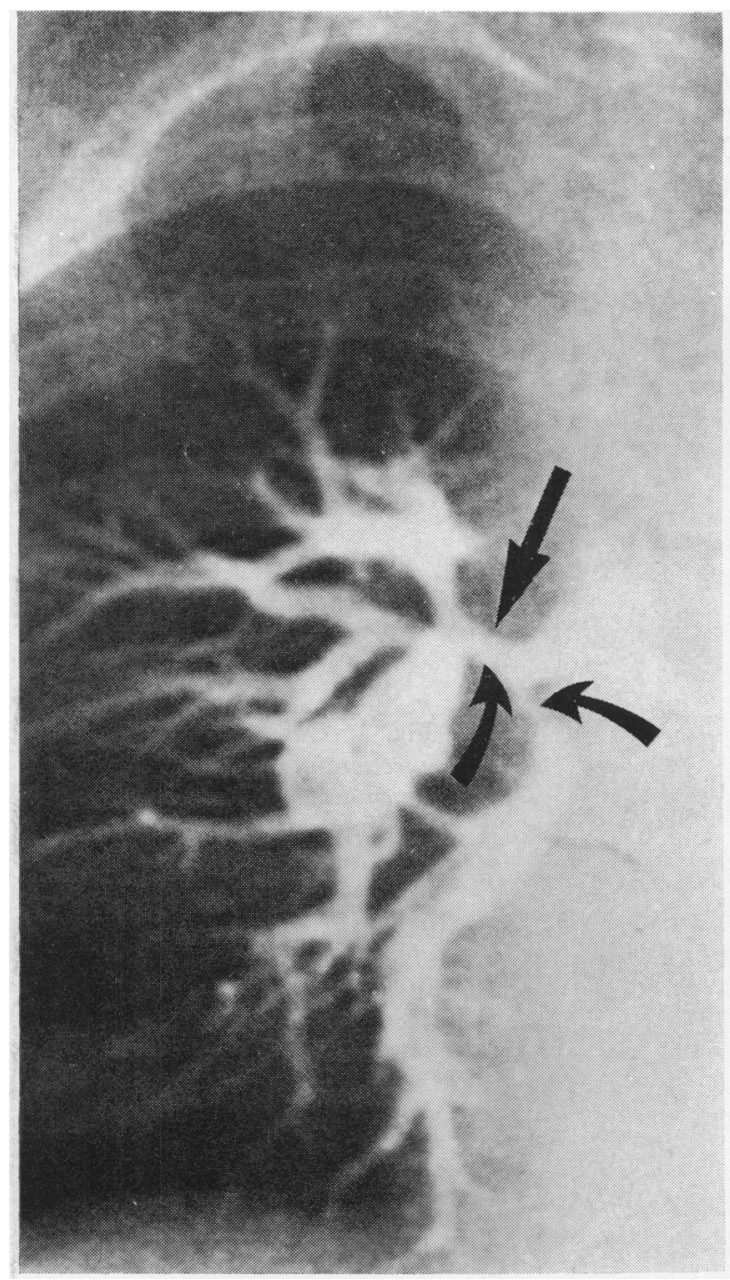

Fig. 4 Case 7. Selective injection into a collateral supplying the right middle lobe and four segments of the lower lobe, showing stenoses $(\rightarrow)$ and segmental arterial dilatation. could not be identified by aortography alone in the remaining case (case 1). Even in the presence of central pulmonary arteries, however, the majority of collateral arteries anastomosed end-to-end with segmental intrapulmonary arteries, providing the only source of blood supply to those segments, and having no connection either with the central pulmonary arteries or their branches within the lung (Fig. 5a and $b$ ). In the three patients without central pulmonary arteries, the maximum number of bronchopulmonary segments connected to one collateral artery varied between three and eight segments per lung.

\section{(2) Central pulmonary arteries}

Preoperatively central pulmonary arteries were shown in five patients (Table). Subsequent thoracotomy disclosed central pulmonary arteries in one additional case, in whom the vessels had not been shown angiographically for two reasons. Firstly, the collateral perfusing the right pulmonary artery was severely stenosed distal to the point of injection (Fig. 6a). Secondly, retrograde flow through the right pulmonary artery was prevented by a stenosis at the origin of that vessel (Fig. 6b). A systemicpulmonary anastomosis was performed to a central vessel in five patients, and, m:stakenly, to an upper lobe artery alone in one.

Appearance : a pre-and postoperative comparison of the central pulmonary arteries was possible in four cases. All four showed a considerable increase in vessel size, but in two cases the vessels still appeared abnormally small. Three stenoses were shown, two of them preoperatively. In addition, two stenoses occurred around the systemic-pulmonary anastomosis, which in cases 1 and 6 had been inserted into an extremely small central pulmonary artery.

Connections : preoperatively, in each lung the central pulmonary artery was seen to connect with only two to four bronchopulmonary segments. Postoperatively, injection of contrast medium into the surgical shunt rather than a collateral artery improved visualisation of the intrapulmonary arteries, and a further seven bronchopulmonary segments were seen to connect with central pulmonary arteries. In each case, however, only five to 11 segments of lung received an increase in blood flow. In case 1 , a subclavian to pulmonary anastomosis into an extremely small right pulmonary artery occluded the origin of two branches to the right upper lobe.

All cases contained at least one lung in which the source of blood supply, either central pulmonary arterial or collateral arterial, was not demonstrated in two to five segments. 


\section{(3) Intrapulmonary arteries connected to central} pulmonary arteries

Preoperatively, the lobar and segmental pulmonary arteries were abnormally small and sometimes had a "spikey" appearance. At the periphery, filling was poor. Only one stenosis was shown preoperatively, in the left lower lobe artery of case 9. Improved postoperative visualisation of the intrapulmonary arteries showed additional abnormalities. In all, seven stenoses were present at either lobar or proximal segmental artery level (Fig. 5b and 6b). Aneurysmal dilatation occurred near the origin of the lower lobe arteries in both lungs in case 6 (Fig. 6b), and dilatation of a segmental artery also occurred distal to a severe stenosis in case 1 . It was difficult to assess change in size of the intrapulmonary arteries after a shunt operation. Arterial opacification was improved by injection through the shunt, giving what may well have been, in some cases, a spurious impression of increase in vessel size. Postoperatively, it was the frequent demonstration of stenoses in both central and intrapulmonary arteries which was the most striking finding and one which made it difficult to evaluate the effect of a shunt on the vessels beyond.
(4) Intrapulmonary arteries connected to collateral arteries

Preoperatively, the intrapulmonary arteries which were connected to collateral vessels frequently appeared abnormal. Eight such intrapulmonary arteries showed a localised dilatation at lobar or segmental level, just distal to a narrowed segment in the collateral artery. Beyond the site of anastomosis with a collateral artery, no localised constrictions of the intrapulmonary arteries were seen. In general, the appearance of the intrapulmonary vessels was related to the size of the collateral artery and the presence or absence of stenoses. Pronounced hypoperfusion was characterised by straight vessels with reduced branching and small vessel haze. Pronounced hyperfusion was characterised by tortuous vessels with side branches and excessive small vessel haze. In between these two extremes came essentially normal appearances. There were also a few segments in case 2 in which the appearances were consistent with severe pulmonary vascular obstructive disease in that the main vessels were dilated and tortuous, but peripheral branching and small vessel haze were reduced.

In three patients without central pulmonary

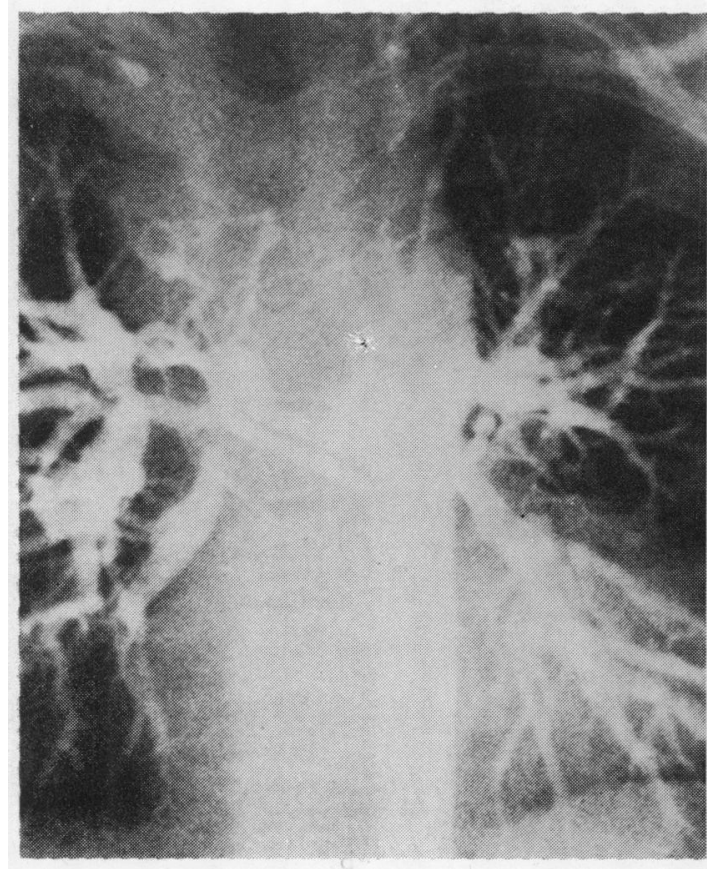

a

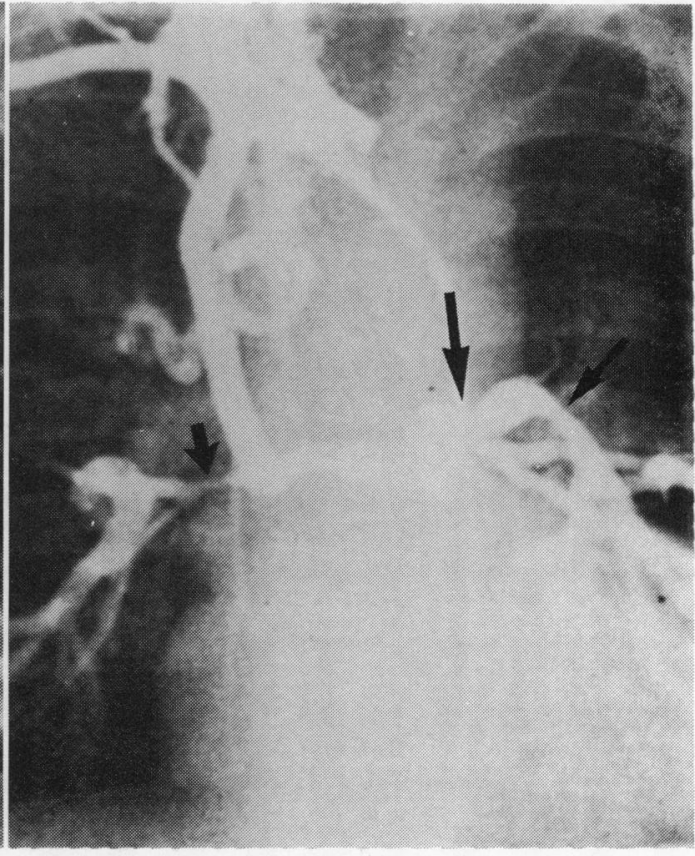

b

Fig. 5 Case 7. (a) Preoperative aortogram. (b) Postoperative angiogram, injection into aortopulmonary anastomosis. Stenoses $(\rightarrow)$. Comparison of $(a)$ and $(b)$ shows a greater proportion of lung connected to collateral than to central pulmonary arteries. 
arteries, the shunt was inserted into a hilar or lobar pulmonary vessel which connected with either five, seven, or nine bronchopulmonary segments. In all cases, aneurysmal dilatation of the pulmonary arteries at lobar level occurred proximal to a stenosis between these and the segmental vessels. The size of the distal intrapulmonary arteries varied. In both cases 2 and 5 a shunt increased flow to four abnormally small segmental arteries. In case 4, however, a shunt to an intrapulmonary artery of the right lung increased perfusion to seven segmental arteries of normal size.

In patients with central pulmonary arteries, those segments of lung connected to a collateral artery alone often contained larger arteries with more lateral branching and more small vessel haze than did those segments connected to the central pulmonary artery, despite the fact that a shunt had been performed (Fig. 5a and $b$ ).

Ligation of collateral arteries in patients with central pulmonary arteries occluded the flow to two segments of the right lower lobe in case 1 and five segments of the right upper and lower lobes in case 3.

\section{Discussion}

In order to develop a rational surgical approach to the management of pulmonary atresia, it is essential to ask what is meant by surgical correction. Repair of the cardiac defect alone is in many cases inadequate, for reasons which will be elaborated later. We shall argue that the pulmonary blood supply also needs correction, but this poses further questions. What precisely needs correcting? What is normal about pulmonary blood supply in this condition, and what is not? And if abnormalities exist, to what extent are they (a) reversible and (b) correctable?

A clear answer to the questions has been made more difficult by lack of clarity in three key areas. Firstly, sources of pulmonary blood supply present at birth have not always been distinguished from acquired collateral circulation, particularly in studies based on older children. Secondly, there has been uncertainty as to the nature of the large systemic arteries perfusing the lungs in this condition, which has in turn led to confusion about the nature of the segments of lung they supply. For if

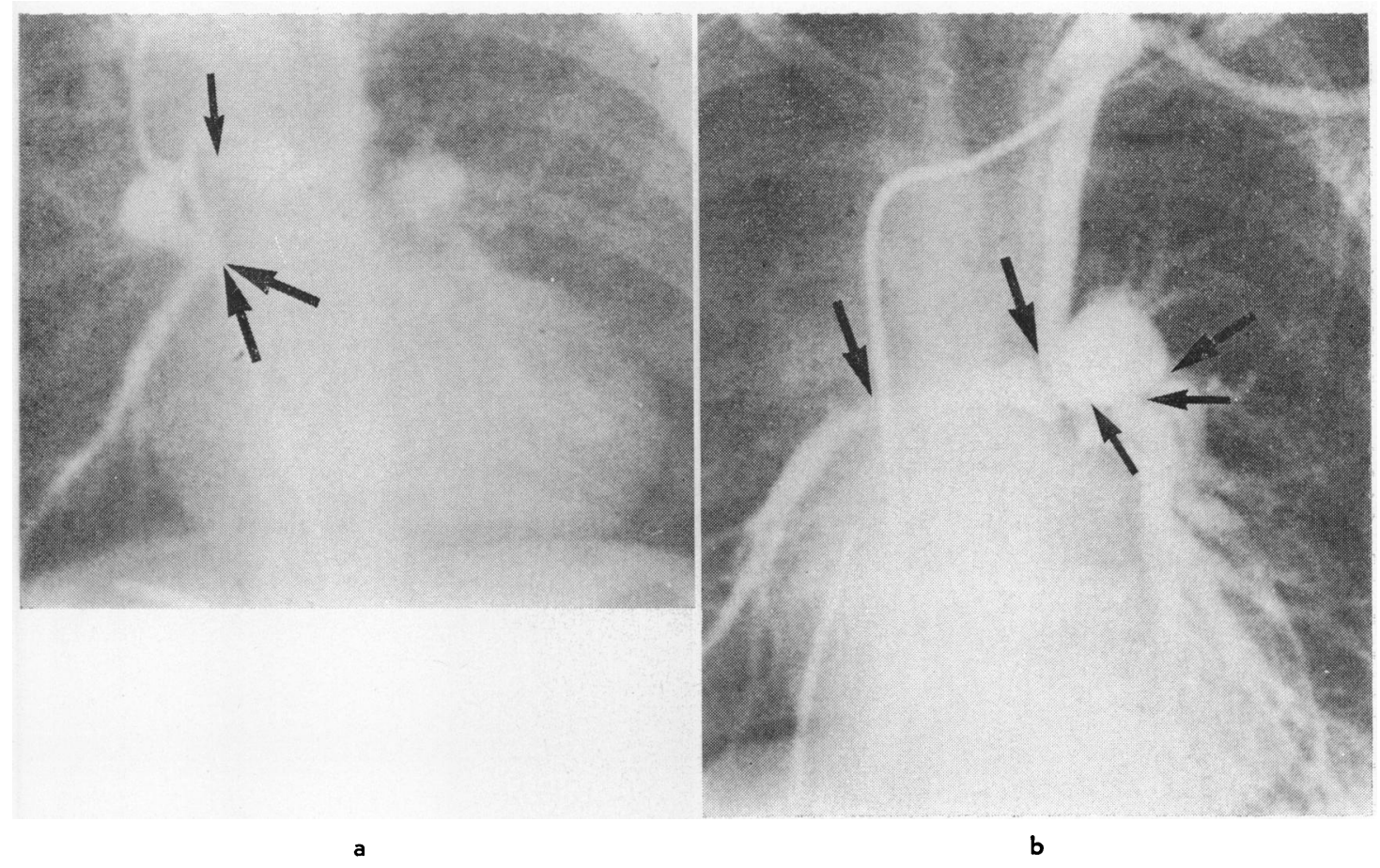

Fig. 6 Case 6. (a) Preoperative injection into stenosed collateral artery (single arrow) perfusing four segments of the right lung. The position of the stenosed origin of the right pulmonary artery is also indicated (double arrow) and is shown in Fig. 6b. (b) Postoperative injection into aortopulmonary anastomosis, showing central pulmonary arteries, stenoses $(\rightarrow)$, and aneurysmal dilatation at origin of left upper and lower lobe arteries. 
these systemic arteries are termed bronchial arteries, the presumption is that the intrapulmonary arteries are also bronchial arteries, and that no normal intrapulmonary arteries exist in these segments. If, on the other hand, the large systemic arteries are termed aortopulmonary collateral arteries, the implication is that they are abnormal connections between essentially normal systemic and normal intrapulmonary arteries. And if normal intrapulmonary arteries exist, complete surgical correction would involve restoration of continuity between the central (intrapericardial) and all peripheral (intrapulmonary) pulmonary arteries. Thirdly, the words "pulmonary artery" or even "the pulmonary artery" have sometimes been used unqualified, leaving uncertainty as to whether reference is being made to central or peripheral vessels.

In many of the patients in the present study some degree of acquired collateral circulation developed between the first and second angiocardiographic study on the side of the thoractomy. This appeared as fine, tortuous arteries arising principally from intercostal arteries and having no direct connection with hilar or intrapulmonary arteries, in contrast to congenital collateral circulation. Acquired collateral circulation presumably increases effective pulmonary blood flow, since the anastomosis is at precapillary level, ${ }^{5}$ but is otherwise disadvantageous, since it will increase pulmonary venous return during cardiopulmonary bypass in an uncontrollable fashion. Because in our cases acquired collateral blood supply formed an unquantifiable but probably small proportion of total pulmonary blood flow, it will not be discussed further.

There is now considerable evidence from histological, ${ }^{16}$ radiographic, ${ }^{78}$ physiological, $^{8}$ and embryological ${ }^{910}$ studies that the large systemic arteries which are present at birth and provide the pulmonary blood supply are not bronchial arteries, which is why we have termed them major aortopulmonary collateral arteries. The same arguments lead to the conclusion that the intrapulmonary arteries in this condition are in essence normal, 18 developing and having the same course, relations, and structure as centrally connected vessels. This study, however, while confirming the general validity of this approach, indicates, as did a previous necropsy study, ${ }^{1}$ that to be in essence normal does not necessarily mean to be in fact normal. Apart from the previously well-documented stenoses in major aortopulmonary collateral arteries, ${ }^{7} 81112$ obstructions were also seen in both central and peripheral pulmonary arteries in the hilar region, much as described by McGoon and colleagues. ${ }^{11}$ The severity of these stenoses was not apparently affected by shunt operations, and complete surgical repair would involve relief of such obstructions. In addition to stenoses, localised dilatations of intrapulmonary arteries at lobar or segmental level were not infrequent, either immediately distal to a major aortopulmonary collateral artery stenosis or proximal to a lobar pulmonary artery stenosis. These dilatations are probably of little haemodynamic significance, but make it difficult to quantify the effect of shunt operations on the growth of the central pulmonary arteries and their continuations in the lung. However, in five patients there was a distinct increase in the size of the central pulmonary arteries after a shunt.

There was also an increase in perfusion at the periphery, but it is uncertain to what extent shunting the central pulmonary artery had reversed the effect of hypoperfusion on lung development. In young children, improving blood flow to underperfused areas of lung should improve the growth of intra-acinar arteries in terms of both the size and number of vessels. ${ }^{13}$ Given that in some patients peripheral perfusion appeared, however, to be less in some shunted segments than in segments perfused by collaterals, it does seem possible that shunting may not always restore the peripheral vasculature to normal. In the present study, the segmental and peripheral pulmonary arteries appeared abnormally small, even when distended by blood and contrast medium, while in the previous morbid anatomical study, ${ }^{1}$ vessels at this level were abnormally small in relation to the size of the accompanying airway, irrespective of whether they were normally connected or isolated. In both studies, the problem within the lung was usually one of hypoplasia. Microscopical quantitative morphometric analysis ${ }^{1}$ has shown a reduction in size and muscularity of the intra-acinar arteries and eccentric areas of intimal proliferation, structural changes compatible with long-standing reduced pulmonary blood flow. ${ }^{14}$

The major problem, however, is that not enough intrapulmonary arteries are connected to the central pulmonary arteries. In contrast to the normal situation when the central pulmonary arteries form a single common pressure head (or focus) for perfusion of the lungs, in pulmonary atresia with ventricular septal defect and major aortopulmonary collateral arteries there is nearly always more than one distinct pressure head so that the pulmonary blood supply is multifocal.

There are now many reports of pulmonary hypertension occurring immediately after surgical correction of pulmonary atresia with ventricular septal defect. ${ }^{15-17}$ This is indeed one of the most important factors affecting immediate surgical 
mortality. ${ }^{17}$ It has been suggested for some time that the most important underlying cause for this is multifocal pulmonary blood supply, ${ }^{5}$ since if the entire cardiac output is forced to pass through a sufficiently limited quantity of pulmonary vascular bed, pulmonary hypertension is inevitable. This theoretical concept has recently received strong support from a study in which the ratio between right and left ventricular systolic pressures, immediately after surgical correction of pulmonary atresia with ventricular septal defect, was predicted from the ratio between the diameter of the proximal right and left pulmonary arteries and the aorta, the body surface area, the presence of stenosis of the right pulmonary artery, and the presence of arborisation anomalies in the pulmonary vascular bed. ${ }^{17}$ This showed that the predicted RV/LV systolic pressure ratio should be raised by 0.85 if bilateral arborisation anomalies are present, by which the authors meant that one lobe or more on each side was not normally connected to a central pulmonary artery.

It is noteworthy that this degree of arborisation abnormality was present in all patients with pulmonary atresia and ventricular septal defect described here, as well as in nearly all patients in a recent necropsy study from this institution. ${ }^{1}$ While it is true that this is a group selected to some extent by the decision not to proceed directly to complete repair, nine other patients underwent "complete" repair during the three years spanning the operation dates for these shunted patients. All survived operation but only two had pulmonary atresia with ventricular septal defect and major aortopulmonary collateral arteries, and one of these died later from infection. In our experience, therefore, the majority of patients with complex pulmonary atresia have a severe arborisation anomaly, and by the criteria of Alfieri and colleagues ${ }^{17}$ are unlikely to survive conventional corrective surgery with an acceptable $\mathrm{RV} / \mathrm{LV}$ systolic pressure ratio. If the arborisation abnormality were also corrected, such patients might survive repair of the cardiac defect.

The results of this study indicate that shunting does not correct the connection problem. Selective injections into isolated major aortopulmonary collateral arteries (those not connected to central pulmonary arteries) showed no change in appearance between the pre- and postoperative studies, indicating that in no case had a shunt into a central pulmonary artery resulted in establishment of perfusion of bronchopulmonary segments not connected to central pulmonary arteries. There was no evidence of an anatomical communication between collaterally connected and normally connected intrapulmonary arteries. The possibility of such communications has not been ruled out, because we have noticed in these and other patients that during selective injection into one major aortopulmonary collateral artery it is occasionally possible to identify "washout" in the lobar pulmonary arteries where non-opacified blood enters from another lobar artery supplied by a different major aortopulmonary collateral artery. In the anatomical study, ${ }^{1}$ however, such communications were sought but not found. Furthermore, if such connections were frequent, it would be exceptional to find side by side an overperfused pulmonary hypertensive segment and an underperfused segment. In reality, this is common.

Given this basic compartmentalisation of pulmonary blood supply, it is clear that however much blood can be forced through the central pulmonary arteries, whether by systemic-pulmonary shunts alone, as here, or by placing conduits between the right ventricle and pulmonary artery without closing the ventricular septal defect, ${ }^{18}$ the "connection problem" will not be solved.

Two possible ways exist of making multifocal blood supply unifocal. One is to ligate isolated major aortopulmonary collateral arteries, in order to encourage compensatory growth of normally connected lung segments, ${ }^{19}$ as the underperfused segments might become relatively smaller. In the small number of cases where this had been carried out, the effect on the total volume of lung normally connected was not detectable. It is preferable to explore the possibility of establishing direct continuity between all segments of lung by creating anastomoses between lobar pulmonary arteries in the region of the hilum, and overcoming the stenoses commonly present at this level. For technical reasons, this operation is carried out during the shunt procedure rather that at the time of complete repair. A division of a collateral artery with interruption of the aortic end and anastomosis of the distal end, either directly or using a Gore-Tex prosthesis, to the central pulmonary artery, is another alternative. We have performed this operation in four patients. This will be the subject of a further report when the follow-up angiograms become available.

\section{References}

1 Haworth SG, Macartney FJ. Growth and development of pulmonary circulation in pulmonary atresia with ventricular septal defect and major aortopulmonary collateral arteries. Br Heart $\mathcal{F} 1980 ; 44$ : 14-24.

2 McKay R, de Leval MR, Rees P, Taylor JFN, Marcartney FJ, Stark J. Postoperative angiographic assessment of modified Blalock-Taussig shunts 
using expanded polytetrafluoroethylene (Gore-Tex). Ann Thorac Surg 1980; in press.

3 de Leval MR, McKay R, Jones M, Stark J, Marcartney FJ. Modified Blalock-Taussig shunt. Use of the subclavian artery orifice as a flow regulator in prosthetic systemic to pulmonary artery shunts. F Thorac Cardiovasc Surg 1980; in press.

4 Foster-Clark AF. Broncho-pulmonary anatomy. In: Perry KMA, Holmes Sellors T, eds. Chest diseases. London: Butterworths, 1963; 1: 19, 21-22.

5 Macartney FJ. The haemodynamics of the abnormal outflow tract. In: Dyde JA, Smith RE, eds. Surgery of the heart. New York: Plenum Publishing Corporation, 1976: 103-17.

6 Thiene G, Frescura C, Bini RM, Valente $M$, Gallucci V. Histology of pulmonary arterial supply in pulmonary atresia with ventricular septal defect. Circulation 1979; 60: 1066-74.

7 Jefferson K, Rees S, Somerville J. Systemic arterial supply to the lungs in pulmonary atresia and its relation to pulmonary artery development. $\mathrm{Br}$ Heart f 1972; 34: 418-27.

8 Macartney FJ, Deverall PB, Scott O. Haemodynamic characteristics of systemic arterial blood supply to the lungs. Br Heart f 1973; 35: 28-37.

9 Congdon ED. Transformation of the aortic-arch system during the development of the human embyro. Contributions to Embryology. Carnegie Institute 1922; 14, nos. 65-71: 47-112.

10 Boyden EA. The time lag in the development of bronchial arteries. Anat Rec 1970; 166: 611-4.

11 McGoon MD, Fulton RE, Davis GD, Ritter DG, Neill CA, White RI Jr. Systemic collateral and pulmonary artery stenosis in patients with congenital pulmonary valve atresia and ventricular septal defect. Circulation 1977; 56: 473-9.

12 Levin DC, Baltaxe HA, Goldberg HP, et al. The importance of selective angiography of systemic arterial supply to the lungs in planning surgical correction of pseudotruncus arteriosus. $A F R$ 1974; 121: 606-13.

13 Hislop A, Reid L. Pulmonary arterial development during childhood: branching pattern and structure. Thorax 1973; 28: 129-35.

14 Best PV, Heath D. Pulmonary thrombosis in cyanotic congenital heart disease without pulmonary hypertension. F Pathol Bacteriol 1958; 75: 281-91.

15 Somerville J, Ross D. Long-term results of complete correction with homograft reconstruction in pulmonary outflow tract atresia. $B r$ Heart $\mathcal{f}$ 1972; 34: 29-36.

16 Doty DB, Kouchoukos NT, Kirklin JW, Barcia A, Bargeron LM Jr. Surgery for pseudotruncus arteriosus with pulmonary blood flow originating from upper descending thoracic aorta. Circulation 1972; 45, suppl 1: 121-9.

17 Alfieri O, Blackstone EH, Kirklin JW, Pacifico AD, Bargeron LM Jr. Surgical treatment of tetralogy of Fallot with pulmonary atresia. $\mathcal{f}$ Thorac Cardiovasc Surg 1978; 76: 321-35.

18 Gill CC, Moodie DS, McGoon DC. Staged surgical management of pulmonary atresia with diminutive pulmonary arteries. $\mathcal{F}$ Thorac Cardiovasc Surg 1977; 73: 436-42.

19 Macartney FJ, Scott O, Deverall PB. Haemodynamic and anatomical characteristics of pulmonary blood supply in pulmonary atresia with ventricular septal defect-including a case of persistent fifth aortic arch. Br Heart $\mathcal{F} 1974$; 36: 1049-60.

Requests for reprints to Dr S G Haworth, Thoracic Unit, The Hospital for Sick Children, Great Ormond Street, London WCIN 3JH. 